\title{
Sistem Pensortiran Barang Berdasarkan Warna Menggunakan Antarmuka Visual Studio
}

\author{
Herlina Putami ${ }^{*}$ \\ ${ }^{1}$ Jurusan Teknik Elektro, Fakultas Teknik Universitas Negeri Padang \\ "e-mail: herlina9982@gmail.com
}

(Diajukan: 30 Juli 2021, direvisi: 06 Agustus 2021, disetujui: 10 Agustus 2021)

\begin{abstract}
Abstrak
Perkembangan teknologi yang sangat pesat memungkinkan para pelaku industri sudah meninggalkan cara manual dengan baralih ke sistem otomasi. Dalam industri, kita mengenal istilah pemisah barang atau sortir barang yang bertujuan untuk memilah barang-barang yang berkualitas baik dengan barang yang berkualitas buruk (reject) . Banyaknya permintaan barang, membuat suatu industri juga memerlukan penyimpanan data pensortiran barang secara otomatis. Tujuan penelian ini adaah untuk mempermudah industri dalam pemilihan barang berdasarkan warna dengan antarmuka Visual Studio dan hasil data jumlah barang yang dapat disimpan dalam Microsoft Exel. Penyortiran barang berdasarkan warna menggunakan sensor TCS3200. Warna yang akan disortir menggunakan warna dasar RGB yaitu Merah, Hijau dan Biru. Sebagai pusat kendalinya adalah Arduino Uno. Terdapat sensor infrared yang digunakan untuk mendeteksi adanya barang, belt konveyor untuk memindahkan barang yang digerakan oleh motor DC, dua motor servo yang akan mendorong barang masuk ke kemasan dan dilengkapi dengan antarmuka Visual Studio 2012 sebagai output dari sistem pemsortiran barang. Hasil dari penelitian ini alat dapat memisahkan warna merah, biru , hijau dan tidak masuk kategori serta antarmuka Visual Studio menampilkan jumlah barang yang masuk secara real time dan mencatat waktu setiap ada barang yang masuk perdetiknya dengan akurat serta data dapat disimpan dalam Microsoft Exel.
\end{abstract}

Kata Kunci: TCS3200, infrared, motor servo, arduino uno, visual studio.

\begin{abstract}
The rapid development of technology has allowed industry players to abandon the manual method by switching to an automated system. In industry, we are familiar with the term goods separator or sorting goods which aims to sort out good quality goods with poor quality goods (reject). The number of requests for goods, making an industry also requires data storage of automatic sorting of goods. The purpose of this research is to make it easier for the industry to choose goods based on color with the Visual Studio interface and the results of data on the number of items that can be stored in Microsoft Excel. Sorting goods by color using the TCS3200 sensor. The colors will be sorted using the basic RGB colors, namely Red, Green and Blue. As the control center is Arduino Uno. There are infrared sensors that are used to detect the presence of goods, a conveyor belt to move goods driven by a DC motor, two servo motors that will push goods into the packaging and are equipped with a Visual Studio 2012 interface as the output of the goods sorting system. The results of this study the tool can separate the colors red, blue, green and not included in the category and the Visual Studio interface displays the number of incoming goods in real time and records the time each item enters per second accurately and the data can be stored in Microsoft Excel.
\end{abstract}

Keywords: TCS3200 , infrared, motor servo, arduino uno, visual studio. 


\section{PENDAHULUAN}

Sistem sortir barang yang dilakukan secara manual memiliki dampak yang sangat besar. Salah satu contohnya adalah pada proses pengepakan masker yang saat sekarang ini masker dapat digunakan dalam aktifitas sehari-hari dengan berbagai macam warna dan bentuk. Penggunaan tenaga manusia dalam sortir barang memicu terjadinya beberapa kesalahan bahkan kegagalan dalam sebuah plant pada produksi industri human error sehingganya output yang didapatkan tidak sesuai harapan (Not Good Product). Imbasnya kualitas barang kurang terjaga dan waktu banyak tersita. Banyaknya permintaan konsumen memungkinkan manusia untuk membuat suatu alat pensortiran barang otomatis.

Beberapa tahun terakhir, para peneliti sudah mulai melakukan research mengenai sistem sortir barang. Sistem sortir barang menggunakan sensor warna TCS3200 untuk mengidentifikasi warna merah, hijau, biru, putih, dan hitam [1]. Sistem sortir barang yang juga menggunakan sensor TCS3000 untuk mendeteksi warna merah, hijau dan biru yang kemudian data warna ditampilkan menggunakan LCD [2], serta mengaplikasikan sensor infrared sebagai media counter dalam menghitung jumlah barang [3]. Sistem sortir barang berbasis arduino yang dilengkapi dengan sensor warna yang dapat dipantau menggunakan Android dengan perantara ESP8266 [4]. Dari beberapa penelitian tersebut masih banyak kekurangan seperti data yang tidak dapat disimpan dan masih menggunakan tampilan LCD yang membuat tampilan menjadi terbatas.

Pada perekonomian digital seperti sekarang ini, sebuah industri membutuhkan suatu peranti lunak (software) yang dapat memberikan data secara cepat dan tepat. Hal ini dimaksudkan agar mempercepat proses pensortiran agar pekerjaan yang dilakukan dapat bekerja secara real time sehingga output yang didapatkan sesuai dengan yang diinginkan dan dapat dilakukan secara terus-menerus [5].Salah satu software berbasis windows yang dapat dijadikan sebagai antarmuka adalah Visual Studio [6]. Software ini menggunakan bahasa pemograman Visual Basic [7]. Visual Basic.NET merupakan salah satu bahasa pemrograman yang dapat digunakan untuk membuat program aplikasi [8]. Visual Basic sendiri menggunakan bahasa yang lebih sederhana dan memiliki tools gratis lebih banyak. Maka dari itu, penulis bermaksud untuk merancang sistem pensortiran barang berdasarkan warna menggunakan antarmuka Visual Studio. Alat ini akan mensortir 3 warna dasar yaitu merah, biru, dan hijau. Dengan menggunakan software Visual Studio 2012 sebagai antarmuka ataupun sebagai output data jumlah barang. Setiap barang yang masuk akan dihitung secara real time dan ditampilkan pada antarmuka Visual Studio. Visual Studio menampilkan jumlah barang yang masuk pada kemasan atau kotak pensortiran dan akan mencatat waktu perdetik setiap ada barang masuk. Kemudian data yang sudah dicatat pada Visual Studio dapat di simpan secara otomatis dalam Microsoft Exel. Penggunaan antarmuka Visual Studio tentunya dapat menghemat biaya dan tenaga pada proses produksi. 


\section{METODE}

Metode ini berupa rancang bangun pensortiran barang berdasarkan warna berbasis Arduino Uno dengan tampilan antarmuka Visual Studio 2012.

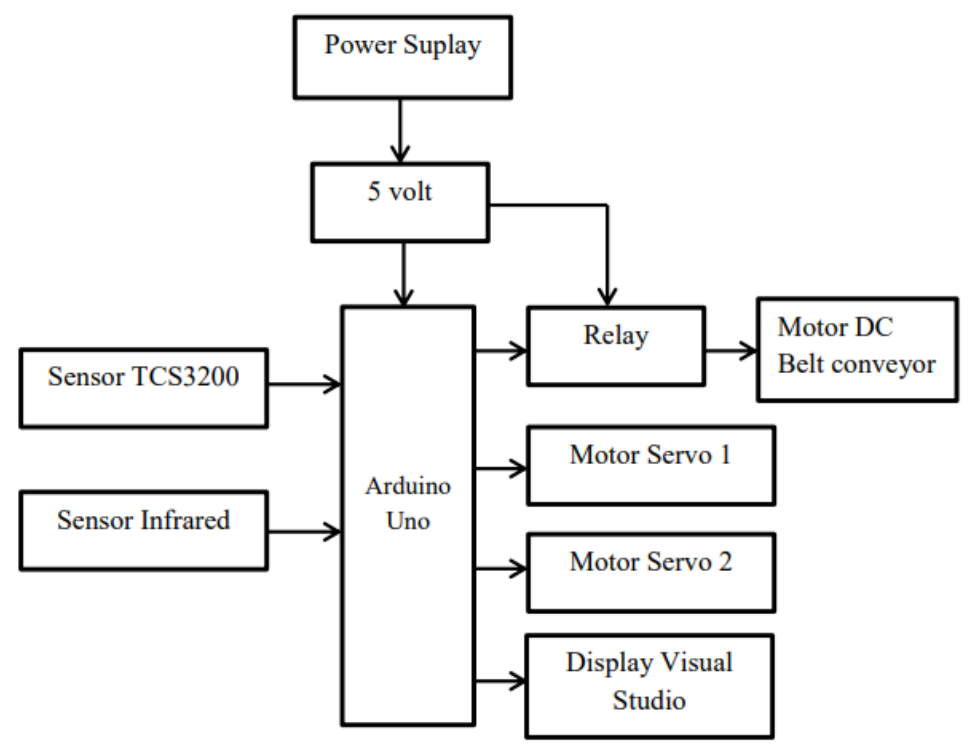

Gambar 1. Blok Diagram

\section{Rancangan Software}

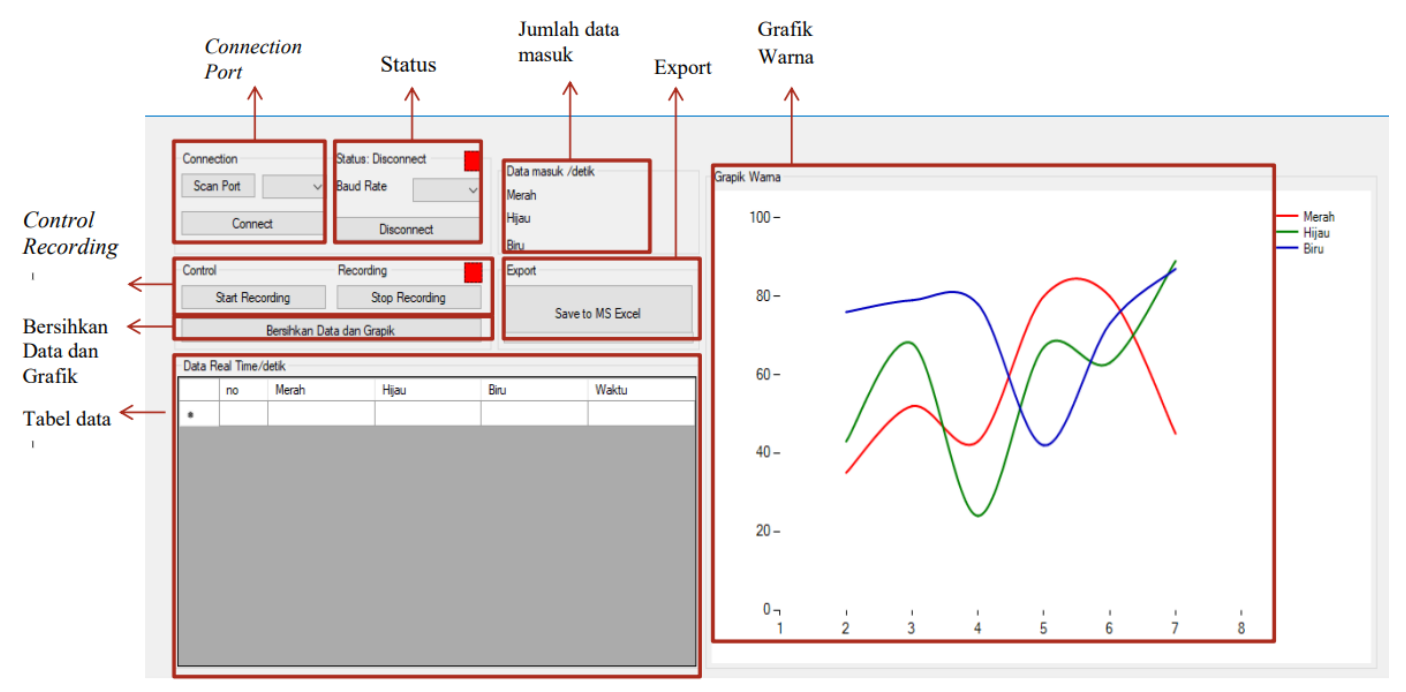

Gambar 2. Rancangan Software Visual Studio. 


\section{Rancangan Mekanik}

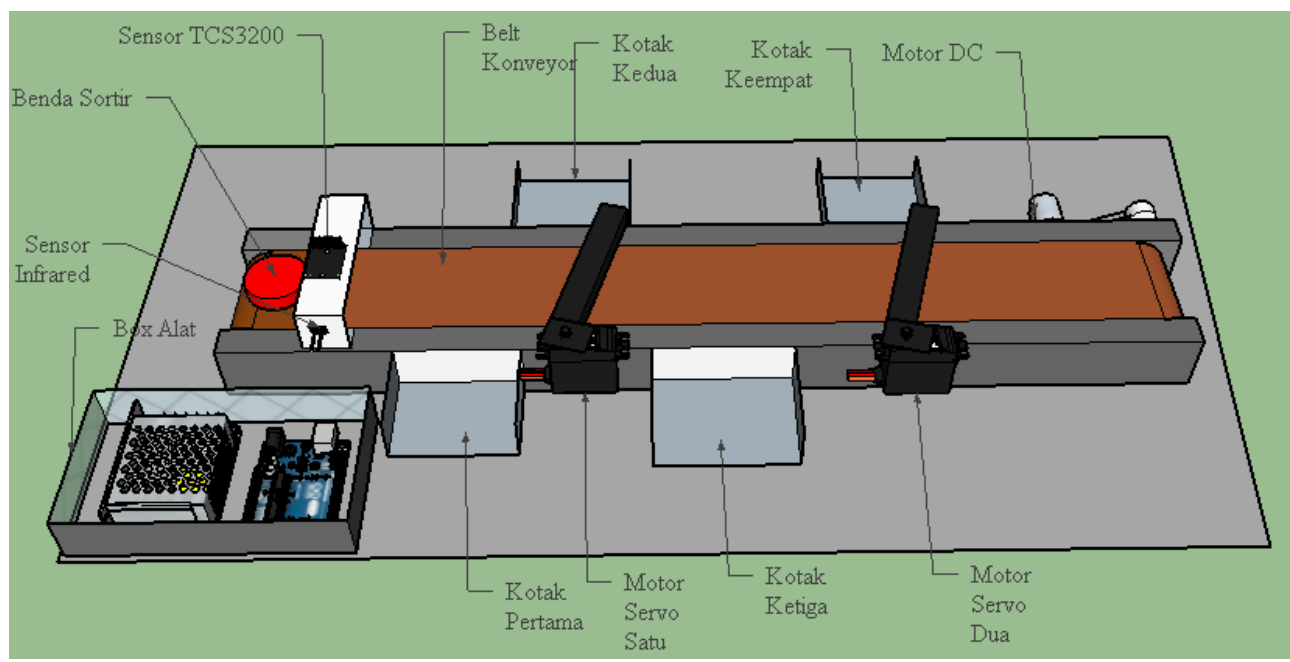

Gambar 3. Sketsa Alat

Flowchart dari hardware yang berfungsi sebagai acuan listing atau tahap-tahan dari cara kerja sistem yang akan dibangun dapat dilihat pada gambar 4 .

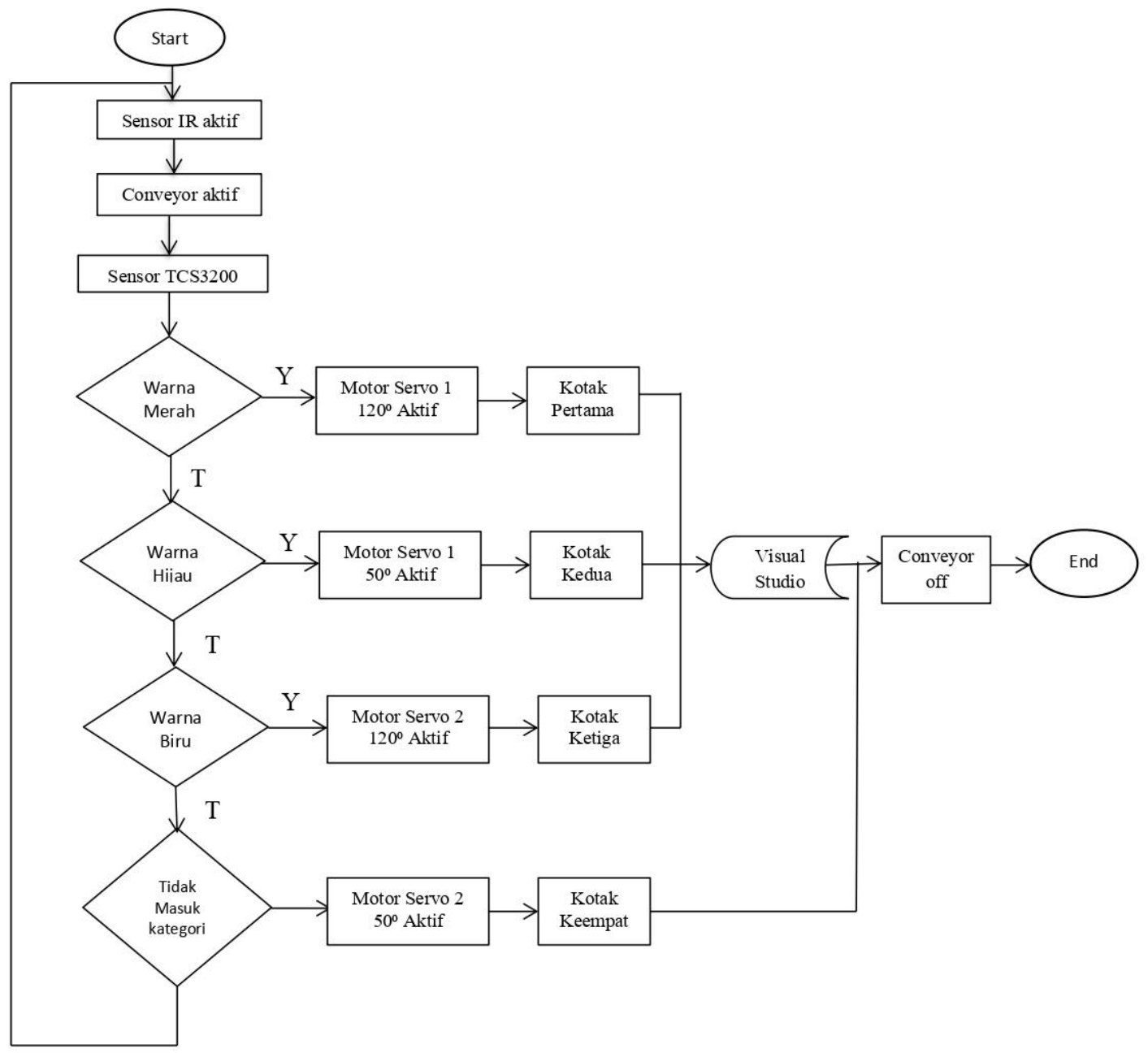

Gambar 4. Flowchart Hardware 
Adapun flowchart software yang berfungsi sebagai acuan dalam membuat listing program serta berisi penentuan intruksi dari premograman sistem dapat dilihat pada gambar 5.

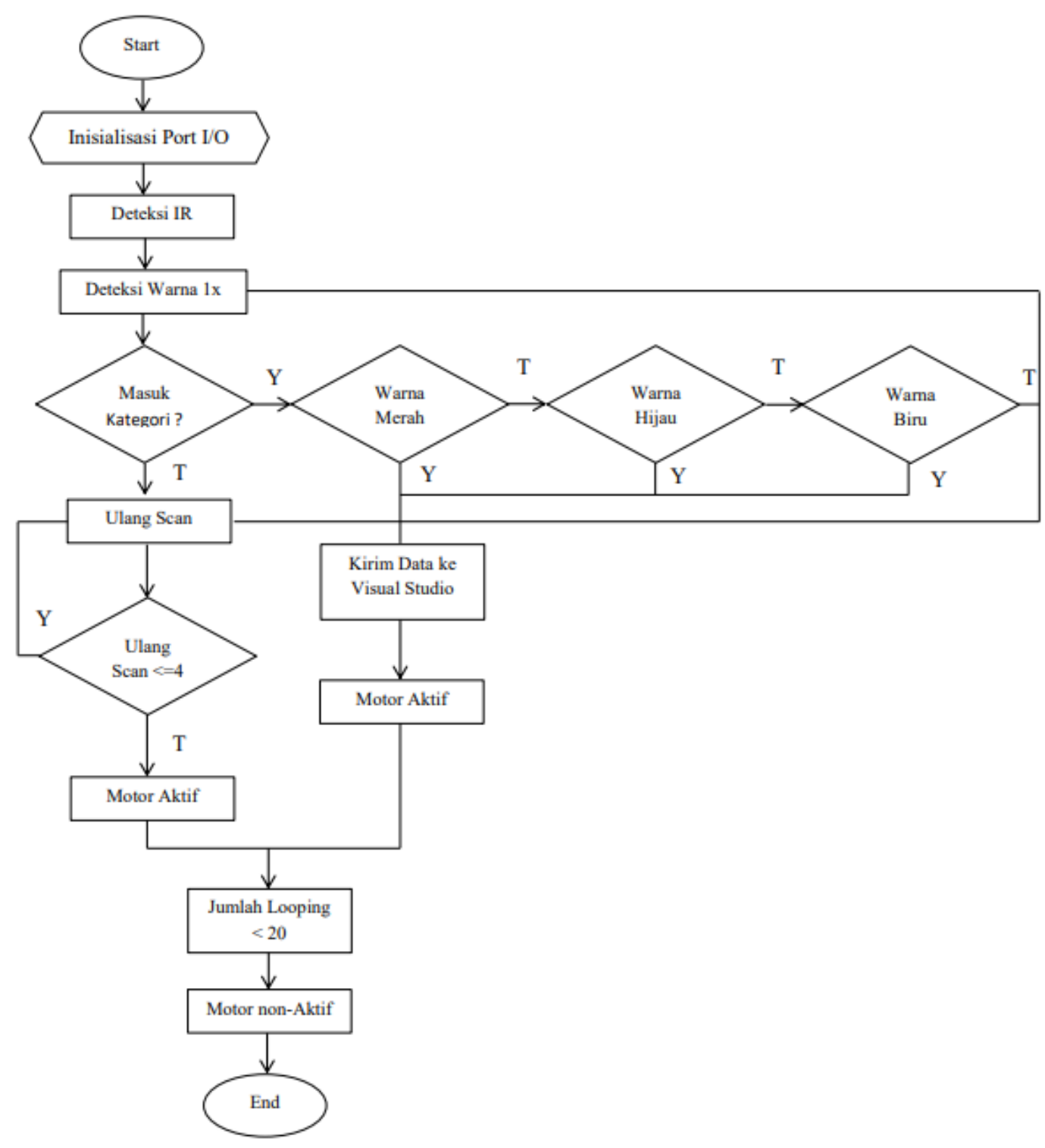

Gambar 5. Flowchart Software

\section{HASIL DAN PEMBAHASAN}

\section{Motor DC}

Pengujian motor DC yang bertujuan untuk mengetahui apakah tegangan supplay yang masuk sesuai dengan jangkauan kerja dari motor DC. Motor DC yang digunakan pada alat ini adalah motor DC dari servo MG996R. Pengujian tegangan motor DC diukur menggunakan multimeter. Motor DC dirangkai bersamaan dengan relay, relay bekerja sebagai saklar untuk mengaktifkan motor DC dengan memberikan logika LOW pada relay, maka motor DC akan aktif atau hidup. 
Tabel 1. Pengukuran Motor DC

\begin{tabular}{ccc}
\hline Logika & Tegangan Motor DC & Relay \\
\hline HIGH & 0 VDC & Normally Open \\
LOW & $5,5 \mathrm{VDC}$ & Normally Close \\
\hline
\end{tabular}

\section{Motor Servo}

Pengujian motor servo bertujuan untuk mengetahui bentuk gelombang PWM pada motor servo. Pengujian ini dilakukan dengan menggunakan Oscilloscope. Dimana posisi awal motor servo disetting pada program Arduino yaitu servo 1 sebesar $175^{\circ}$ dan servo 2 sebesar $180^{\circ}$. Pada tabel 2 dapat dilihat hasil dari pengujian motor servo 1 dan motor servo 2 terhadap perubahan gelombang arah putaran motor.

Tabel 2. Pengujian Perubahan Posisi Motor Servo

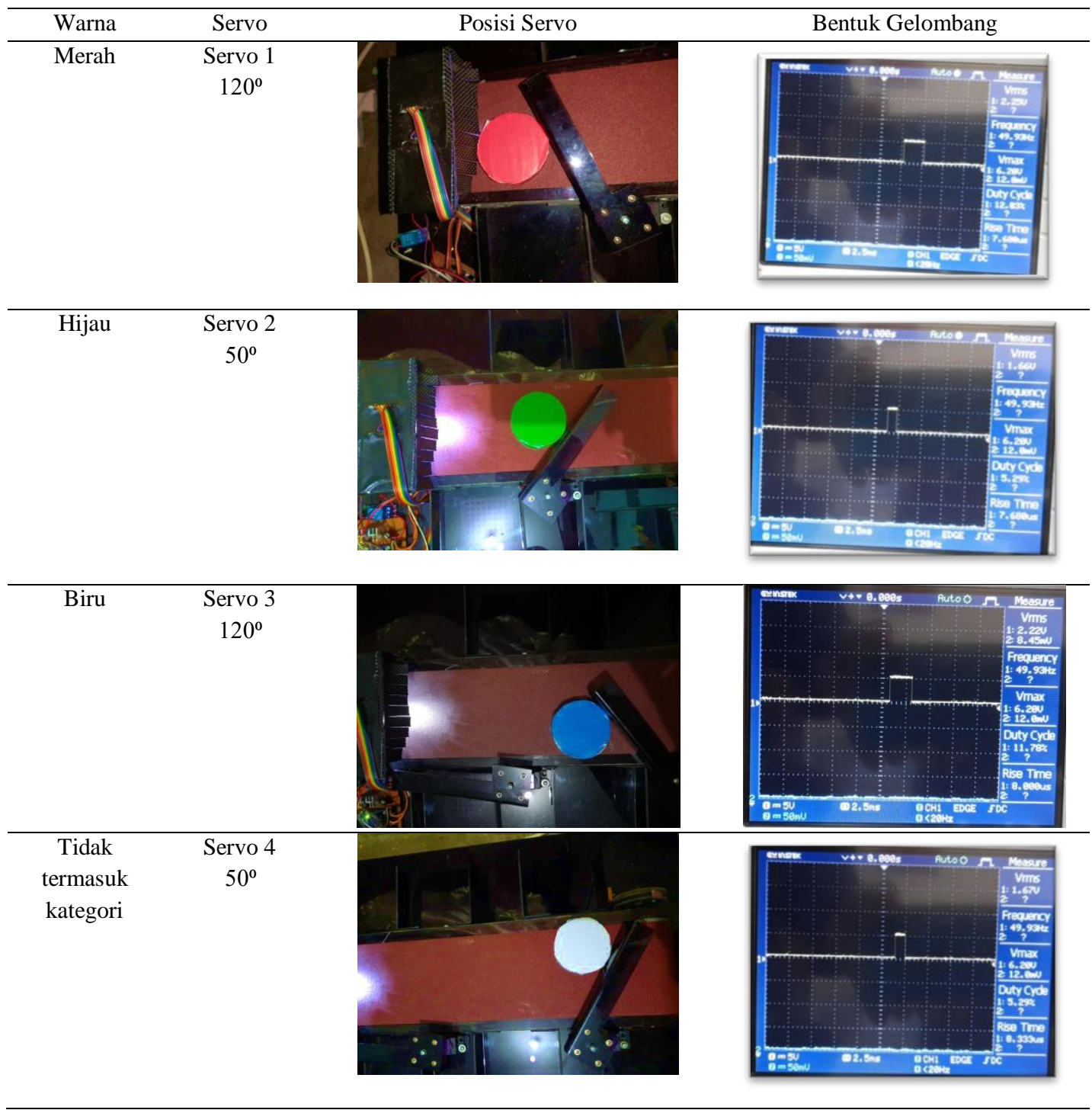

\section{Sensor Infrared}

Sensor infrared pada alat ini menggunakan satu buah LED infra merah dan satu buah photodiode yang dipasang berhadapan. LED infra merah yang dilengkapi dengan rangkaian untuk membangkitkan data yang akan dikirim pada photodiode, photodiode 
berfungsi untuk menerima sinar inframerah yang dikirimkan oleh pemancar[9].Berikut rangkaian sensor infrared :

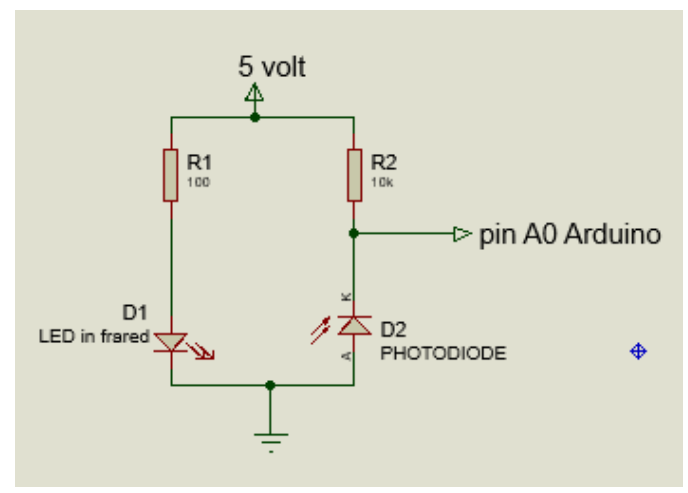

Gambar 6. Rangkaian Sensor Infrared

Pengujian pada sensor infrared dengan memberikan rentang nilai sensor pada program Arduino Uno yaitu ketika saat sensor mendeteksi adanya benda nilai ir kecil dari 200. Apabila ada benda maka photodiode menerima pantulan cahaya inframerah sedikit dan hambatan photodiode akan mengecil begitupun sebaliknya jika tidak ada benda photodiode menerima pantulan cahaya inframerah banyak dan hambatan photodiode akan besar. Adapun pengujian nilai infrared terlihat pada COM 5 Arduino Uno dapat dilihat pada Gambar 7 dan Gambar 8.

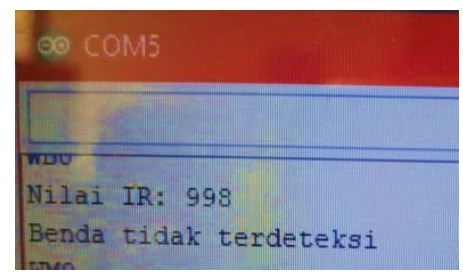

Gambar 7. Nilai sensor infrared saat benda tidak terdeteksi

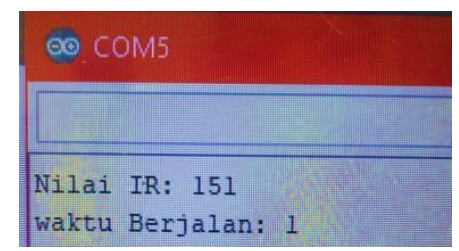

Gambar 8. Nilai sensor infared saat mendeteksi adanya benda

\section{Sensor TCS3200}

Pada pengujian benda diletakan $1 \mathrm{~cm}$ dibawah sensor TCS3200, warna yang akan di uji yaitu warna merah, hijau dan biru, selain warna tersebut berarti warna tidak termasuk kategori. Pengujian warna tersebut disetting berdasarkan nilai RGB pada sensor TCS3200 yang sudah dirangkai dengan Arduino Uno. Nilai RGB hanya tampil di serial monitor aplikasi Arduino pada COM5 komputer atau laptop seperti pada Gambar 9 . 


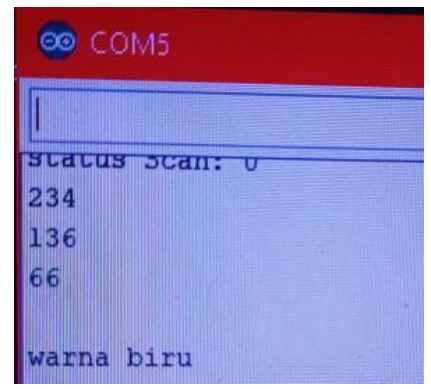

Gambar 9. Nilai RGB Monitor Arduino pada COM5

\section{Pengujian Keseluruhan}

Pengujian sistem seperti pada Gambar 10, pensortiran barang berdasarkan warna terhubung langsung dengan antarmuka Visual Studio 2012. Sebagai tegangan sumber untuk menghidupkan alat yaitu 220 volt.

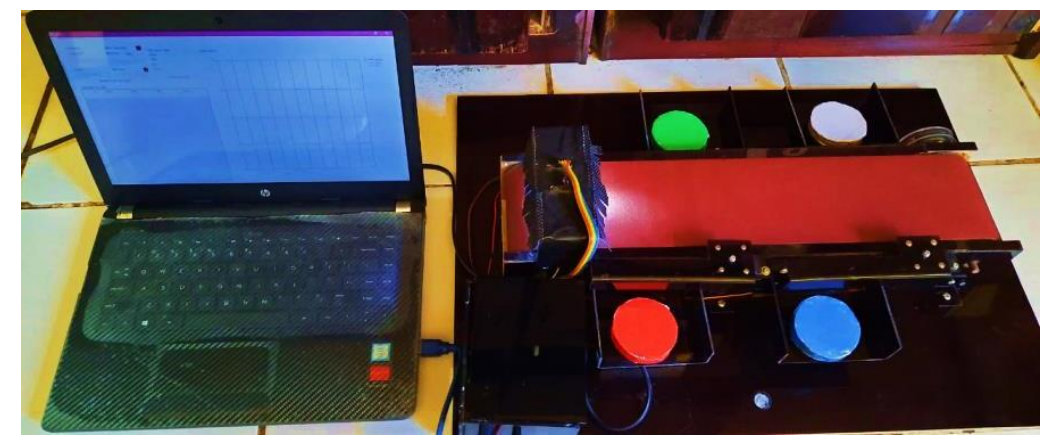

Gambar 10. Pengujian Alat Keseluruhan

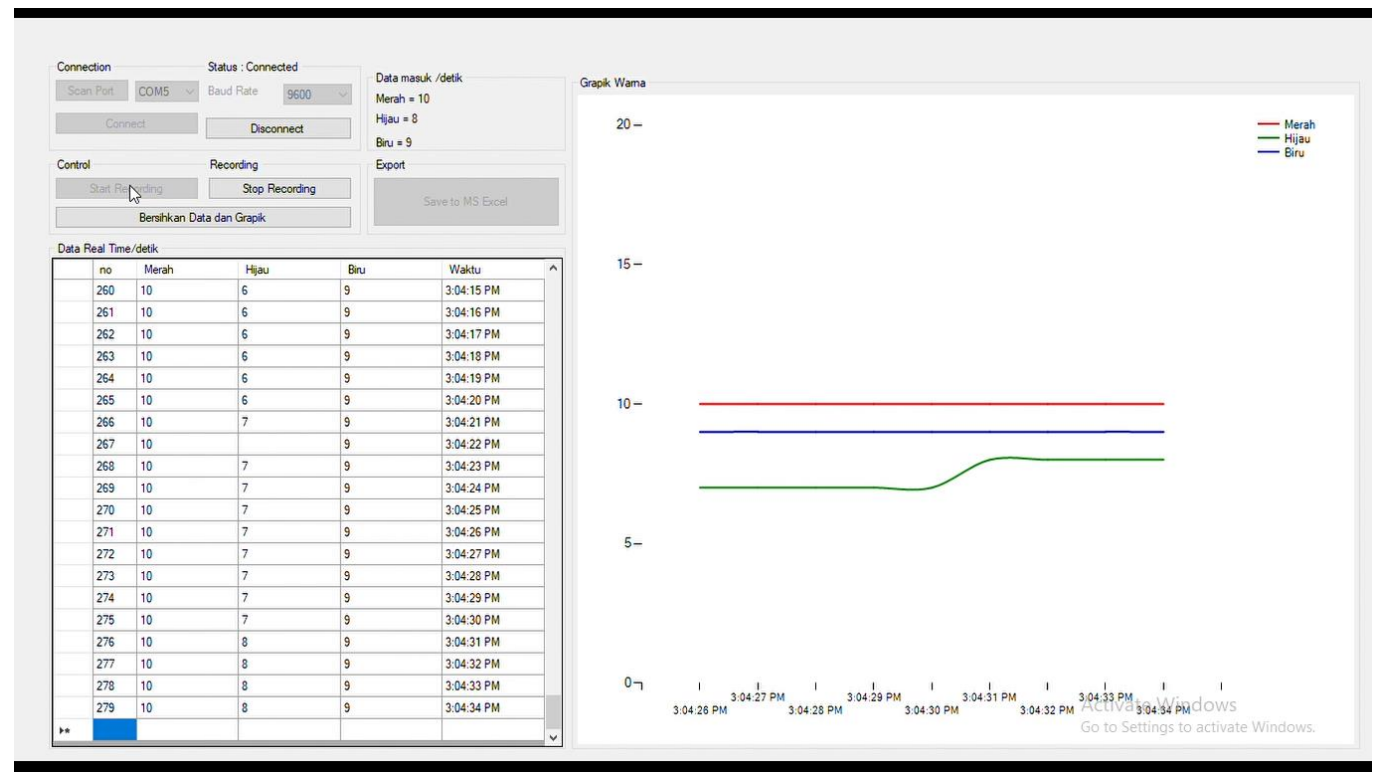

Gambar 11. Tampilan Antarmuka Visual Studio 2012

Gambar 11 merupakan tampilan antarmuka Visual Studio 2012 yang menampilkan jumlah pensortiran barang serta mencatat waktu ketika barang tersebut masuk ke kemasan, barang yang akan dihitung hanya barang yang berwarna merah, biru dan hijau. Selain itu, data penghitung barang dapat dilihat padan Microsoft Excel. Nilai 
jumlah barang dan waktu yang tercatat dapat disimpan dalam bentuk data exel seperti pada gambar 11.

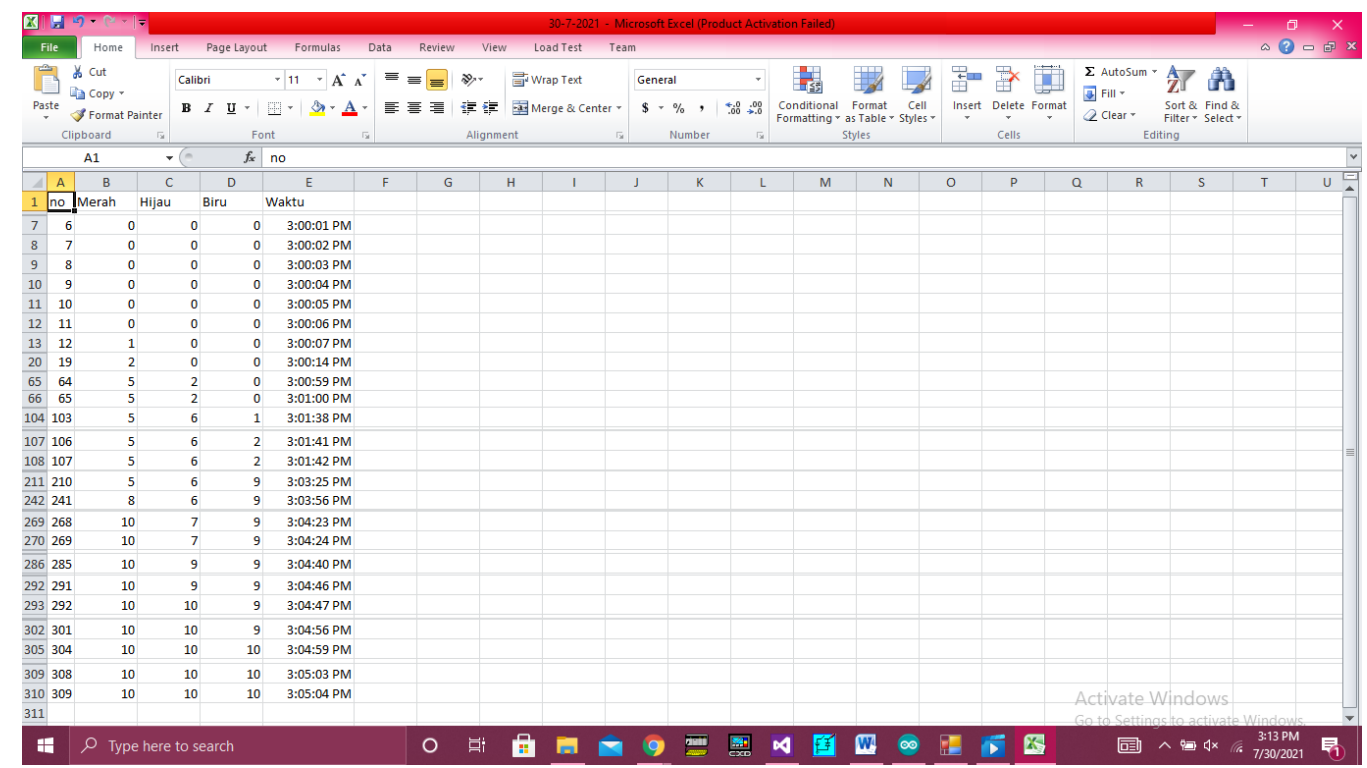

Gambar 11. Data Penghitungan pada MS Excel

\section{KESIMPULAN}

Sistem pensortiran barang berdasarkan warna menggunakan antarmuka Visual Studio 2012 berjalan dengan baik dari penelitian sebelumnya yang tidak dapat menyimpan data jumlah barang secara otomatis. Pengujian sistem pensortiran barang pada alat ini, sensor TCS3200 dapat mengenali warna merah, biru ,hijau dan benda tidak masuk kategori, sensor infrared dapat mendeteksi adanya benda , relay dapat mengaktifkan motor DC untuk memutar belt konveyor, adapun motor servo dapat mendorong barang sesuai kotak yang disediakan dan antarmuka Visual Studio dapat menampilkan hasil penghitungan barang yang masuk pada pensortiran serta data pensortiran dapat disimpan pada Microsoft Excel. Hal ini diharapan dapat memudahkan pengguna dan menghemat biaya pada proses sortir barang.

\section{REFERENSI}

[1] M. I. Sari, R. Handayani, S. Siregar, and B. Isnu, "Pemilah Benda Berdasarkan Warna Menggunakan Sensor Warna TCS3200," TELKA - Telekomun. Elektron. Komputasi dan Kontrol, vol. 4, no. 2, pp. 85-90, 2018, doi: 10.15575/telka.v4n2.85-90.

[2] W. Rahman and M. Yuhendri, "Prototype Smart - Conveyor Untuk Sortir Barang Berdasarkan Warna Berbasis Atmega8535," pp. 1-10, 2019.

[3] A. Safaris and H. Effendi, "Rancang Bangun Alat Kendali Sortir Barang Berdasarkan Empat Kode Warna," JTEV (Jurnal Tek. Elektro dan Volasional), vol. 06, no. 02, pp. 399-410, 2020.

[4] T. W. Wisjhnuadji, A. Narendro, and P. Wicaksono, "Sistem Sortir Barang Otomatis Berbasis Arduino Dengan Sensor Warna Dan Monitoring Via Android,"

Fakt. Exacta, vol. 13, no. 2, pp. 106-112, 2020, doi: 
10.30998/faktorexacta.v13i2.6586.

[5] M. N. Rifai and B. Upayarto, "Sistem Informasi Pendapatan Dengan Menggunakan Visual Studio 2017 Dan Mysql Pada Sdit Insantama Bandung," TEDC, vol. 15, pp. $1-7,2017$.

[6] B. Josef et al., "Perancangan Antarmuka Pendulum Terbalik Menggunakan Visual Studio," -Proceeding Eng., vol. 6, no. 2, pp. 2818-2825, 2019.

[7] D. Fernando, "Monitoring Penggunaan Daya Listrik Satu Fasa MSI Transaction on Education," MSI Trans. Educ., vol. 01, no. 04, pp. 176-182, 2020.

[8] R. A. Hidayat, K. I. Satoto, and A. F. Rochim, "Perancangan Sistem Pemantau Ruangan Dengan Webcam Menggunakan Bahasa Pemrograman Visual Basic . Net," Transient, vol. 1, 2012.

[9] N. Qomariyah, R. Wirawan, P. S. Fisika, U. Mataram, and A. Uno, "Aplikasi Sensor Infrared Dan Arduino Uno Untuk Alat Peraga Sederhana Gerak Jatuh Bebas," Pros. PKM-CSR, vol. 1, pp. 23-25, 2018. 